Cadernos de Estudos Sociais e Políticos, Rio de Janeiro, vol. 6, 2018.

\title{
Por Un Nuevo Órden De Las Cosas: A Imprensa e o Sistema Unitário Na Presidência De Bernardino Rivadavia (1826)
}

\author{
Por Un Nuevo Orden De Las Cosas: The Press and the Unitary System in the Presidency of Bernardino \\ Rivadavia (1826)
}

Juliana da Silva Sabatinelli ${ }^{1}$

\section{RESUMO}

Este artigo pretende apresentar como as ideias unitárias de poder se consolidaram entre as províncias que hoje formam a Argentina na década de 1820 através da figura política de Bernardino Rivadavia, o primeiro presidente "argentino" em 1826. Para difundir esse projeto de Estado, a imprensa foi a principal disseminadora das ideias e o veículo formador de opinião durante essa presidência tornando público o projeto unitário para as províncias, os embates com os grupos federais e o plano de uma Constituição em uma conjuntura marcado pela crise interna e externa. Nesse cenário, a questão da soberania guiou os debates acerca da organização política desejada pelas províncias e foi o principal motivo do fracasso do projeto rivadaviano em 1827. A partir dessas ideias, é possível aproximar a historiografia brasileira da argentina e pontuar questões relevantes para cada país no contexto estudado.

PALAVRAS-CHAVE: Rivadavia, Unitarismo, Guerra com Brasil, Constituição.

\begin{abstract}
This article intends to present how the unitary ideas of power were consolidated among the provinces that today form Argentina in the 1820s through the political figure of Bernardino Rivadavia, the first "Argentine" president in 1826. To disseminate this state project, the press was the main disseminator of ideas and the vehicle that formed opinion during this presidency, making public the unitary project for the provinces, the clashes with federal groups and the plan of a Constitution in a conjuncture marked by the internal and external crisis. In this scenario, the issue of sovereignty guided the debates about the political organization desired by the provinces and was the main reason for the failure of the rivadaviano project in 1827. From these ideas, it is possible to approximate the Brazilian historiography of Argentina and score relevant issues for each country in the context studied.
\end{abstract}

KEYWORDS: Rivadavia, Unitarianism, War with Brazil, Constitution. 
Cadernos de Estudos Sociais e Políticos, Rio de Janeiro, vol. 6, 2018.

\section{POR UN NUEVO ÓRDEN DE LAS COSAS: A IMPRENSA E O SISTEMA UNITÁRIO NA PRESIDÊNCIA DE BERNARDINO RIVADAVIA (1826)}

A história argentina é um campo pouco conhecido pela historiografia brasileira. Nosso contato com os historiadores e historiadoras portenhos se resume a alguns temas, como a Guerra da Cisplatina, a Guerra do Paraguai e, em menor escala, o contexto das Ditaduras latino-americanas e a experiência do Peronismo. Esse pequeno contato demonstra o quanto precisamos absorver com a historiografia dos países vizinhos e a importância de um olhar descolado dos grandes centros de pensamento histórico.

Em se tratando de projetos de Estado, esse distanciamento pode ser maior. Por isso, o presente artigo pretende apresentar o projeto unitário de poder desenvolvido em meados da década de 1820 e fortalecido pela presidência de Bernardino Rivadavia entre as Províncias Unidas do Prata. Esse governo durou cerca de sete meses e marcou os anos de 1826 e 1827 como um período em que as províncias puderam apostar na organização da nação política. Isso se deu dez anos após a independência definitiva frente a Espanha, e dezesseis anos após a Revolução de Maio. O contexto era a Guerra com Brasil (ou Guerra da Cisplatina, segundo a historiografia brasileira) e a necessidade de um exército para enfrentar as forças do Império fez com que o Congresso de 1824 elegesse Rivadavia como o primeiro presidente da "República Argentina".

Bernardino Rivadavia nasceu em Buenos Aires em 20 de maio de 1780 (Belsunce, Floria, 1975). Participou das questões que envolveram o primeiro levante contra a metrópole espanhola (a Revolução de 25 de Maio de 1810) e votou contra a continuidade do vice-rei. Quando o Triunvirato se organizou em 1811, foi nomeado Secretário de Governo e Guerra e, a partir desse momento, a figura política de Rivadavia prevaleceu e se tornou protagonista, chegando a ser considerado pelos três homens que constituíam o Triunvirato como um quarto pilar político. Alguns problemas fizeram com que o Triunvirato se diluísse e tal situação fez com que Rivadavia se afastasse do cenário portenho, e fosse viver e estudar em Londres até 1820. Sua ascensão na política como Ministro se deu durante a década de 1820, nomeada pela historiografia argentina como "Anarquía de los años 20", quando recebeu o cargo de Ministro de Governo e promoveu algumas reformas importantes na política, na economia e no centro urbano de Buenos Aires. É

2 A expressão aparece entre aspas pois é utilizada conforme está presente no texto da Constituição de 1826. $<$ http://americo.usal.es/oir/legislatina/normasyreglamentos/constituciones/argentina1826.pdf $>$ Acesso em $11 \mathrm{de}$ junho de 2020. 
Cadernos de Estudos Sociais e Políticos, Rio de Janeiro, vol. 6, 2018.

importante pontuar que o posto de ministro de Governo ocorreu um pouco depois do retorno de Rivadavia a Buenos Aires, após sua estadia em Londres. (Ternavásio, 2013).

No tempo em que viveu na Europa, Rivadavia conheceu as ideias do Utilitarismo desenvolvidas na Inglaterra por Jeremy Bentham e James Mill. O princípio da utilidade determinava que as ações humanas deveriam ser julgadas segundo graus de dano ou prazer que tais ações proporcionam à comunidade: atitudes corretas geram felicidade, enquanto que as erradas, provocam danos às pessoas. Para Bentham, a busca pelo bem-estar da maioria estaria ligado diretamente ao trabalho dos legisladores considerados responsáveis pela administração da sociedade. Dessa forma, a necessidade de ampliar os níveis de liberdade de expressão seria o melhor caminho para a fundamentação do ideal de "república ilustrada" já que era o ingrediente especial para a consolidação de um governo democrático (Gallo, 2008).

Para criar uma "republica ilustrada", a liberdade de expressão foi expandida com a criação de novas associações e com a expansão da imprensa jornalística que permitiriam ampliar o debate público e o acesso ao conhecimento. A organização da Biblioteca pública e de associações tais como as Academias de Medicina, de Ciências Físicas e Matemáticas, de Música, e da "Sociedad Literaria" (esta última, responsável pela publicação do jornal mais importante da época, o periódico El Argos de Buenos Aires, e da revista La Abeja Argentina), junto à instituição da "Ley de Prensa" de 1821, que estimulou o surgimento de novos jornais e papéis públicos, caracterizaram o conjunto de medidas rivadavianas como uma "feliz experiência", que foi coroada com a fundação da Universidade de Buenos Aires em 1821 (Ternavásio, 2013).

$\mathrm{Na}$ política, Rivadavia procurou colocar as ideias utilitaristas dentro do Congresso Nacional, na tentativa de organização política do país. Esse Congresso, que aconteceu de 1824 até 1827, é considerado pela historiografia argentina como a terceira tentativa de organização nacional e como um espaço de inúmeras discussões conceituais sobre nação, Estado, República, povo, ordem e soberania. Esses debates dão ao Congresso a ideia de um foro de lenguajes, espaço de formação de conceitos.

Essa terceira tentativa significou um outro caminho para a organização nacional diante de um contexto sem liderança nem modelo político em vigor. São dos debates e discursos dos deputados que boa parte dos conceitos e ideários políticos foram originados nesse contexto, principalmente os argumentos acerca do conceito de soberania, sentimento tão caro às províncias.

Na América Espanhola a voz da soberania se constituiu como uma "arma de guerra", que condicionou a extensão e delimitação dos novos estados. Duas concepções de soberania estiveram em constante disputa: uma indivisível e uma plural; essa última podia 
Cadernos de Estudos Sociais e Políticos, Rio de Janeiro, vol. 6, 2018.

integrar os diferentes corpos políticos em uma associação maior sem perder a soberania frente à figura da União (Goldman, 2014, p. 40, tradução livre).

No Rio da Prata a soberania estava diretamente ligada à construção do projeto nacional. (Goldman, 1998) A posição da soberania construiu esses debates: a união não questionava a soberania dos pueblos, preocupação maior das províncias desde o processo de autogoverno colocado em 1810; por outro lado, a unidade estava associada à soberania do centro e traduzia a necessidade de que os pueblos e províncias obedecessem a governos instalados na capital.

A historiadora argentina Nora Souto (2008) comenta que essa relação de obediência ao centro não diminuiu a soberania dos pueblos, tanto que nas tentativas anteriores de organização política nacional, os representantes eram eleitos por voto. Entretanto, união remetia à ideia de pacto entre as províncias, colocando em funcionamento o princípio da soberania dos pueblos. Para sanar esse problema, a Lei Fundamental de 1825, pacto entre as províncias, reconhecia a soberania das províncias ao oficializar que a organização nacional teria um papel secundário na política provincial até que as unidades de poder se organizassem internamente.

O que os representantes não contavam era com a Guerra com o Brasil, declarada em 1825 por Dom Pedro I diante do desejo brasileiro pela manutenção da posse da Cisplatina e da defesa de Buenos Aires em trazer a Banda Oriental para as províncias unidas. Esse conflito, que deu origem ao Uruguai, trouxe problemas para os países envolvidos. Para as províncias do Rio da Prata, fez com que os representantes precisassem investir em exército para a guerra; na prática, deputados de outras províncias alegaram que o conflito era responsabilidade de Buenos Aires e preferiram não se envolver. Daí a ascensão de Rivadavia à presidência. Tendo maioria no Congresso e com a proposta da unidade de poder sem afetar a soberania provincial, em 6 de fevereiro de 1826 o primeiro presidente foi eleito, ferindo a Lei Fundamental de 1825 e o pacto entre as províncias.

Esta electo D. BERNARDINO RIVADAVIA Presidente de las Provincias Unidas del Río de la Plata.

Concluyó la primer hora de sesión. En la segunda, se tomó en consideración y se sancionó el decreto siguiente:

Art 1. Queda nombrado para Presidente de las Provincias Unidas del Río de la Plata el ciudadano D. Bernardino Rivadavia, con arreglo á la ley sancionada en el dia 6 del corriente. (Mensagero Argentino, 7 de febrero de 1826, n. 24)

A partir desse panorama é possível entender que a chegada de Rivadavia à presidência não foi bem recebida pela maioria das províncias. Além de ter violado a Lei Fundamental, Rivadavia sancionou a Constituição de 1826 com caráter unitário, indo de encontro à questão da soberania 
Cadernos de Estudos Sociais e Políticos, Rio de Janeiro, vol. 6, 2018.

das províncias e apresentou ao Congresso o projeto da Lei de Capitalização, segundo o qual Buenos Aires passaria a ser a capital do poder nacional da República Argentina.

O presidente Rivadavia também não agradou o grupo federal no Congresso, já que a maioria de suas ações políticas iam de encontro com o princípio da soberania das partes defendido pelos representantes federais. O aumento das tensões se deu com a Constituição de 1826, documento elaborado sob as ideias Utilitárias e que fundamentou o sistema unitário de poder. De acordo com o texto, a soberania emanaria dos três poderes; porém, as liberdades eram restritas, já que o Executivo detinha uma parcela maior de poder que os demais. O documento também secularizava o Estado, estabelecia os parâmetros de votação e organizava as câmaras de deputados e senadores. Porém, a soberania estava no poder central, junto à capital, Buenos Aires. Se o documento de 1819, anterior ao de 1826, era pouco claro com relação ao modelo de governo adotado, a Constituição do período rivadaviano declarava no artigo 7 que "A nação argentina adota para seu governo a forma representativa republicana, consolidada em unidade de regime". (Ternavásio, 2013, p. 155)

Sobre a centralização do governo e do poder na província de Buenos Aires, o historiador argentino Ignacio Zubizarreta (2014) destaca que a província - e a cidade, em alguns momentos desempenhava papel de "administradora da crise", já que desde o período colonial concentrava as relações com a Metrópole e, por isso, era mais madura politicamente.

\footnotetext{
No entanto, eram a falta de riqueza e desenvolvimento, a ausência de pessoal capacitado, a escassa população e o envolvimento político quase ausente dos governadores o que fazia das províncias unidades soberanas. Desse modo, afastadas de seu pai - a Coroa Espanhola - o filho mais velho deveria ocupar-se de cuidar de seus irmãos órfãos mais novos, incapacitados de fazer algo por si mesmos. Desse modo, o que Buenos Aires tentava era unir uma soberania que, segundo a perspectiva do Unitarismo, existia previamente, e que de forma provisória havia se debilitado por "dimensões puramente domésticas" (Zubizarreta, 2014, p. 66. Tradução livre).
}

Ainda que a situação dentro do Congresso não fosse tão boa, a imprensa que apoiava Rivadavia desempenhou um importante papel de disseminar bons argumentos sobre os feitos do governo e sobre a Constituição. Ao longo de sua jornada política, inúmeros jornais expunham suas ideias, as leis propostas, os debates entre os representantes e a visão dos editores sobre as medidas propostas pelo presidente, dentre eles El Argos de Buenos Aires (1822-1825), El Correo Nacional (18251826) e El Mensagero Argentino (1825-1827).

A aproximação de Rivadavia com a imprensa se deve muito pelas ideias utilitárias de liberdade de expressão. Entretanto, é possível classificar Rivadavia como um letrado patriota, conceito de Jorge Myers sobre homens que, no século XIX, foram responsáveis pela construção 
Cadernos de Estudos Sociais e Políticos, Rio de Janeiro, vol. 6, 2018.

de um ideário político em meio às consolidações Estatais entre as antigas colônias espanholas da América do Sul. Parte das medidas em nome do debate público e do acesso ao conhecimento introduzem Rivadavia nesse conceito, pois ainda que suas ideias fossem disseminadas majoritariamente via textos jornalísticos, suas ideias encabeçaram importantes acontecimentos nesse contexto, como o aumento considerável de jornais circulando nas e entre as províncias. (Myers, 2009).

Dentre os periódicos que apoiaram Rivadavia, destaca-se o Mensagero Argentino. Esse jornal circulou de novembro de 1825 até julho de 1827, sendo a coluna "Interior" responsável por disseminar a ordem do dia, alguns debates do Congresso e responder provocações de jornais opositores sobre o contexto da época. Além disso, procurou comentar a Guerra contra o Brasil, apontar problemas de algumas províncias e divulgar temas econômicos importantes para o comércio entre as partes. (De Marco, 2006)

De maneira geral, o jornal desempenhou seu papel de construção de opinião pública, em um contexto de forte circulação jornalística. Sendo um "pedagogo" do povo (González, 2008), as páginas do Mensagero e de tantos outros cumpriram a função de dar suporte à propaganda revolucionária e conferir legitimidade ao poder, pela identificação dessa opinião com a vontade do povo soberano.

Assim, a construção do projeto unitário pelas palavras do jornal teve relação direta com a presidência de Rivadavia: estabelecer a nova ordem das coisas diante da ausência de um Estado nacional. Para dar força a esse projeto, os editores comentaram a necessidade de um líder, uma cabeça, capaz de organizar as províncias num sistema político que, de alguma maneira, beneficiasse a todas. Essa cabeça concentraria a ordem e organizaria as províncias sob um sistema unitário, ou seja, o poder emanaria a partir de Buenos Aires.

Esta base é dar a todos os povos uma cabeça, um ponto capital que a todos regule e
apoie: em ela não há organização nas coisas nem subordinação nas pessoas, e como será
funesto se os interessem ficarem como estão no presente, sem um centro que seja
garantia de seu cumprimento para que cresçam circulando e multipliquem fecundizando
tudo; é preciso que tudo o que forme a capital seja exclusivamente nacional. (Mensajero
Argentino, 14 de fevereiro de 1826$)^{3}$

A construção da opinião pública foi versada na ideia de que o governo rivadaviano inaugurou uma nova ordem das coisas políticas entre as províncias há tanto desejosas da

3 "Recibimiento del Sr. Presidente de la Republica de las Provincias Unidas del Río de la Plata." In El Mensajero Argentino, 14 de febrero de 1826, n. 26, p. 2. Tradução Livre. 
Cadernos de Estudos Sociais e Políticos, Rio de Janeiro, vol. 6, 2018.

organização nacional por meio da Constituição. (Goldgel, 2014) O sistema unitário, nas palavras dos editores, traria essa nova ordem das coisas no cenário do Rio da Prata.

$\mathrm{Na}$ prática, quando os deputados levaram a Constituição de 1826 para suas províncias, o rechaço foi notório. As realidades provinciais eram desconformes ao que Rivadavia tinha contato, e os unitários não conseguiram se introduzir nessas diversas realidades em 1826. A aceitação do documento que acirrou o centralismo também não foi favorável à presidência de Rivadavia, já que a maioria das províncias com organização política havia estabelecido governos com autonomia provincial. É possível pensar que o presidente, por essa perspectiva, desconhecia a realidade das províncias do interior.

A esperança da organização nacional começou a se desfazer após o rechaço provincial da Constituição, que não vigorou. Os conflitos com o Brasil ganhavam contornos de desgaste, fazendo com que o ministro das relações exteriores de Rivadavia tentasse dois acordos fracassados com D. Pedro I. Somado a isso, o empréstimo do banco inglês, destinado aos gastos da guerra, fazia falta na administração pública, deixando em aberto as inúmeras dívidas contraídas desde o processo de independência. Os estancieiros do interior, protegidos pela Lei de enfiteusis, que ampliou o acesso às terras públicas a fim de ocupar as regiões mais ao sul, começaram a perceber que as terras dadas pelo Estado não davam o lucro desejado e a aproximação desses senhores com a autonomia das províncias se tornou nítida.

A guerra que uniu as províncias com o primeiro presidente das Províncias Unidas foi a mesma que tirou Rivadavia de seu sillón, colocando as partes mais uma vez em um cenário politicamente instável e marcado por disputas entre unitários e federais. A escolha política de Rivadavia foi renunciar ao poder em julho de 1827, deixando para os deputados e para a facção unitária os ônus do processo. A terceira tentativa de organização Estatal havia fracassado.

\footnotetext{
En una situación de absoluta debilidad, producto de la oposición de las provincias a la Constitución dictada poco tiempo antes, la guerra civil desatada en el interior y la falta de apoyo en la misma Buenos Aires, Rivadavia decidió desconocer una paz tan deshonrosa y renunció a sua cargo de presidente en junio de 1827 (Ternavásio, 2013, p. 159).
}

O que se seguiu foi uma quarta tentativa de formação do Estado por meio de Manuel Dorrego, principal opositor do projeto unitário e inimigo de Mensagero Argentino. Em 1827, Dorrego assumiu o governo de Buenos Aires e resolveu o conflito com o Império do Brasil. Os federais haviam chegado ao poder e permaneceram nesse status até a queda definitiva de Juan Manuel de Rosas em 1852, quando as querelas políticas entre federais e unitários ganharam novas roupagens. 
Cadernos de Estudos Sociais e Políticos, Rio de Janeiro, vol. 6, 2018.

Em dezembro de 1826, talvez percebendo a crise que 1827 traria para as Províncias Unidas, os editores do Mensagero procuraram defender o jornal enquanto disseminador de informações e formador de opinião, demonstrando aos leitores todo empenho desse veículo de notícias:

não ficou um só pensamento que não se tenha analisado com clareza possível. [o jornal] El Mensagero quase deve abandonar estes caminhos que já estão trilhados e deixar ao julgamento das mesmas províncias o fardo sobre a existência ou a ruína, sobre a vida ou a morte da República. (Mensagero Argentino, 24 de dezembro de 1826. Tradução livre)

O Mensagero Argentino se manteve até a renúncia de Rivadavia em julho de 1827, defendendo suas investidas políticas e tentativas de se manter no poder. O desfecho desse veículo denota que o projeto unitário encontrou força e forma na figura política de Rivadavia, já que a história desse grupo político apresenta baixas significativas de 1826 até 1852, quando o partido foi totalmente ressignificado.

Assim, ligar Rivadavia à nova ordem das coisas por meio do projeto unitário de poder é perceber, por meio da imprensa, como que essas ideias se tornaram públicas, ouvidas e aceitas por parte das províncias. Ao mesmo tempo, sendo o novo algo a ser experimentado, essa ordem centralista desagradou a outra parte das províncias que, buscando seus próprios ordenamentos, se afastaram das demandas de Buenos Aires.

Apesar do governo de Rivadavia apresentar-se original ao contexto, dentro da historiografia argentina ainda existem silêncios bastante significativos. (Zubizarreta, 2013) Boa parte dos trabalhos sobre o governo rivadaviano se refere aos problemas na Guerra, à ascensão de Rosas, e ao governo federal instalado após 1827. O surgimento de alguns trabalhos sobre o Unitarismo entre as províncias do Rio da Prata aconteceu devido à historiografia argentina revisionista, que desde os anos 1990 procura retornar ao passado histórico para estudar temas pouco desenvolvidos e construir melhores visões sobre temas importantes, dentre eles o conceito de caudillo e o que se configurou como projeto federal entre as províncias. Nesse caminho, o unitarismo aparece como oposição ao modelo federal na maioria dos trabalhos, tendo em vista que as ideias do Federalismo entre as províncias do Prata seguiram em desenvolvimento após a renúncia de Rivadavia, encontrando maior expressão a partir da década de $1830{ }^{4}$

Mesmo assim, a historiografia sobre os Unitários é recente, fazendo com que alguns historiadores realmente comentem sobre esse grupo político. É o caso de Ignacio Zubizarreta, que

4 Sobre as ideias federalistas e seu desenvolvimento político entre as províncias a partir da década de 1830 , consultar Herrero (2009) e Chiaramonte (2016). 
Cadernos de Estudos Sociais e Políticos, Rio de Janeiro, vol. 6, 2018.

procura conversar com os historiadores mais importantes da Argentina, Túlio Halperín Donghi e Sergio Bagú, e desenvolver suas impressões a respeito das ideias e do grupo unitário em si.

Donghi e Bagú, junto a Ignacio Zubizarreta, buscaram entender a oposição ao federalismo entre as províncias do Rio da Prata. Sergio Bagú (1974) comenta sobre os unitários dizendo que a origem da facção se encontraria em um grupo político desprendido do rivadaviano, constituindo assim uma facção heterogênea. Bagú também aponta que a facção não foi exclusivamente porteña e que o que caracterizou os unitários não foi o centralismo político materializado por eles junto a Rivadavia, mas sim suas intenções reformistas e o desejo de modernizar o Estado e a organização social. Túlio Halperín Donghi (1972), ao contrário de Bagú, aponta que os unitários estariam próximos aos fazendeiros e não voltados à questão do nacional na economia, mas que de maneira geral se constituíram em um grupo político importante para a história das províncias.

Na historiografia brasileira, o silêncio sobre os Unitários é mais profundo devido aos quase inexistentes estudos sobre a presidência de Rivadavia. A Guerra da Cisplatina, que faz ponte com a chegada de Rivadavia ao poder, é, em grande maioria, estudada sob a perspectiva militar e as ações nas fronteiras do Rio Grande do Sul e na relação do conflito com a crise do Primeiro Reinado 5 .

O silêncio na historiografia brasileira se refere também à vida de Rivadavia que, após renunciar à presidência em 1827, escolheu o Rio de Janeiro para viver com sua família. Rivadavia viveu no bairro de Botafogo, no final do século XIX, onde recebeu alguns compatriotas em sua residência e trocou cartas com antigos companheiros de seus tempos áureos na política. Alguns intelectuais como Juan B. Alberdi e Tomás de Iriarte fizeram-lhe visitas e, por meio das memórias que escreveram, é possível saber sobre sua estadia no Rio, já que se tornou um homem pouco sociável e as notícias sobre sua vida na cidade brasileira são escassas. Após a morte da esposa, Rivadavia foi para Espanha, onde faleceu no dia 2 de setembro de 1845, ressentido com Buenos Aires e com toda situação política que se passava na região.

A importância desse trabalho é, portanto, fazer da presidência de Rivadavia um exemplo de opção de organização Estatal, comparando as inúmeras possibilidades que D. Pedro I tinha quando viabilizou o processo de independência do Brasil. Somado a isso, é também despertar na historiografia brasileira, que pouco estuda os processos de independência e constituição do Estado nacional nos países de colonização espanhola, o interesse historiográfico por esses países e suas particularidades. Ademais, contribuir para que as tensões que levaram à Guerra da Cisplatina sejam melhor compreendidas, gerando trabalhos e pesquisas referentes a outro olhar sobre os conflitos

5 Para entender a relação da Guerra com a crise do Primeiro Reinado, consultar Pereira (2012). 
Cadernos de Estudos Sociais e Políticos, Rio de Janeiro, vol. 6, 2018.

pela Banda Oriental. Essa agenda de pesquisa será somada ao conhecimento sobre a história das províncias que constituem a atual Argentina, país tão próximo ao Brasil, mas tão pouco conhecido pela nossa academia.

\section{BIBLIOGRAFIA}

ARAMBURO, Mariano José. Estado, Soberanía, Nación y otros conceptos conexos en el Río de la Plata, 1824-1827. Buenos Aires: Ariadna histórica. Lenguajes, conceptos, metáforas. 2012.

BAGÚ, Sergio. Los unitarios. El partido de la unidad nacional, en: Unitarios y Federales, A.A. V.V. Buenos Aires: Gránica, 1974.

BELSUNCE, César A. García; FLORIA, Carlos Alberto. Historia de los Argentinos. Buenos Aires: Editorial Kapeluz, 2a ed., 1975, tomo I e II.

CHIARAMONTE, José Carlos. Raíces históricas del Federalismo Latinoamericano. Buenos Aires: Sudamericana, 2016.

DE MARCO, Miguel Ángel. Historia del Periodismo Argentino. Desde los orígenes hasta el Centenario de Mayo. $1^{a}$ ed. Buenos Aires: Educa, 2006.

DONGHI, Tulio Halperin. De la Revolución de Independencia a la Confederación Rosista. Espanha: Editoral Paidós, 2000.

GALLO, Klaus. Bernardino Rivadavia. El primer presidente argentino. Buenos Aires: Edhasa, 2012.

GOLDGEL, Víctor. Cuando lo nuevo conquistó América. Prensa, moda y literatura en el siglo XIX. Buenos Aires: Siglo Veintiuno Editores, 2014.

GOLDMAN, Noemí, SALVATORE, Ricardo. Caudillismos Rioplatenses. Nuevas miradas a un viejo problema. 2a ed. Buenos Aires: Eudeba, 2005.

, Nueva História Argentina. Tomo 3. Buenos Aires: Editorial Sudamericana, 1998 (pdf)

$<$ https://ens9004-infd.mendoza.edu.ar/sitio/nueva-historia-

argentina/upload/Nueva Historia Argentina Tomo 3.pdf> Acesso em 12 de junho de 2020.

GOLDMAN, Noemí. Soberanía en Iberoamerica. Dimensiones y dilemas de un concepto politico fundamental, 1780-1870. In SEBASTIÁN, Javier Fernández (dir.). Diccionario político y social del mundo iberoamericano. Conceptos políticos fundamentales, 1770-1870. Madrid: Centro de Estudios Políticos y Constitucionales - Universidad del País Vasco, 2014, tomo II, p. 40. (pdf) $<$ https://pt.scribd.com/doc/120572899/Noemi-Goldman-Soberania $>$ Acesso em 10 de junho de 2020 . 
Cadernos de Estudos Sociais e Políticos, Rio de Janeiro, vol. 6, 2018.

GONZÁLEZ, Pilar. Civilidad y Politica en los orígenes de la nación argentina: las sociabilidades en Buenos Aires, 1829-1862. Buenos Aires: Fondo de Cultura Económica, 2018.

HALPERÍN DONGHI, T. Revolución y guerra. Formación de una elite dirigente en la Argentina criolla. Buenos Aires: Siglo XXI, 1972.

HERRERO, Fabián. Federalistas de Buenos Aires 1810-1820. Sobre los orígenes de la política revolucionaria. $1^{\circ}$ ed. Remedios de Escalada: De la Universidad Nacional de Lanús, 2009.

MYERS, Jorge. El Letrado patriota: los hombres de letras hispano-americanos en la encrucijada del colapso del imperio español en América. In: ALTAMIRANO, Carlos (dir). Historia de los intelectuales en América Latina. Buenos Aires: Katz Editores, tomo I, 2009.

PEREIRA, Aline Pinto. A monarquia constitucional representativa e o locus da soberania no Primeiro Reinado: Executivo versus Legislativo no contexto da Guerra da Cisplatina e da formação do Estado no Brasil. UFF: Tese de Doutorado em História Social, 2012.

SEBASTIÁN, Javier Fernández (dir.). Diccionario politico y social del mundo iberoamericano. Madrid: Centro de Estudios Políticos y Constitucionales, 2009 y 2014, 11 vols. em 2 tomos. (pdf) Os arquivos dos verbetes presente no volume I estão disponíveis em http://www.iberconceptos.net/pt-pt/dicionario-politico-e-social-do-mundo-iberoamericano. Acesso em 12 de junho de 2020.

SOTO, Nora. Unidad/Federación. In: GOLDMAN, Noemí. Lenguaje y revolución. Conceptos politicos clave en el Río de la Plata, 1780-1850. Buenos Aires: Prometeo Libros, 2008, p. 175-192.

TERNAVÁSIO, Marcela. História de la Argentina. 1806-1852. Buenos Aires: Editores Siglo Veintiuno, 2013.

ZUBIZARRETA, Ignacio. Los unitarios. Faccionalismo, prácticas, construcción identitaria y vínculos de una agrupación decimonónica, 1820-1852. Berlin: Tese de Doutorado, 2011.

Por los senderos de una relación displicente: La renovación historiográfica argentina y el unitarismo. Serie Documentos de Trabajo. Buenos Aires: Universidad del CEMA, 2013, n. 518. < https://www.econstor.eu/bitstream/10419/84470/1/767435877.pdf $>$ Acesso em 12 de junho de 2020.

Unitarios. Historia de la facción política que diseñó la Argentina Moderna.

Buenos Aires: Editorial Sudamericana, 2014. 